\title{
Nutritional dynamics during the development of xylophagous beetles related to changes in the stoichiometry of 11 elements
}

\author{
M I C H A $€$ F I L I P I A K and J A U A R Y WEINER \\ Institute of Environmental Sciences, Faculty of Biology and Earth Sciences, Jagiellonian University, Kraków, Poland
}

\begin{abstract}
The present study examines the adaptive strategy used by wood-boring beetles to compensate for the lack of nutrients in dead wood. The contents of nutritional elements in growing wood-boring beetles (Stictoleptura rubra L. and Chalcophora mariana Dejean) are compared with the elemental composition of decaying dead wood (pine stumps), showing changes during the beetles' ontogenetic (i.e. larval) development. The stoichiometric ratios of $\mathrm{C}$ and other nutritional elements ( $\mathrm{N}, \mathrm{P}, \mathrm{K}, \mathrm{Na}$, $\mathrm{Ca}, \mathrm{Mg}, \mathrm{Fe}, \mathrm{Zn}, \mathrm{Mn}$ and $\mathrm{Cu}$ ) are investigated to identify the most important nutrients for larval development. The degree of nutritional mismatch that is encountered by the beetle larvae changes dramatically over 3-4 years of simultaneous larval growth and wood decay. Excluding $\mathrm{C}$, the relative contents of nutritional elements increase substantially in decaying wood, whereas the opposite tendency is found in larvae, most likely because of carbon deposition in fat. The elements limiting larval development because of their scarcity in dead wood are N, P, K, Na, Mg, Zn and Cu. Fungal activity (i.e. the transport of nutrients from the surrounding environment to decaying stumps) can explain the observed mitigation of the original mismatch, although prolongation of the larval development time is still necessary to compensate for the scarcity of some of the required elements in food.
\end{abstract}

Key words. Beetle, deadwood, ecological stoichiometry, fungi, life history, wood eater.

\section{Introduction}

Dead wood is one of the most abundant food resources in terrestrial ecosystems. However, its extreme nutritional deficiency poses great challenges for xylophages because it results in severe stoichiometric mismatches (Denno \& Fagan, 2003; Hessen et al., 2013). These mismatches may hamper or prevent the development of saproxylic species (Filipiak \& Weiner, 2014; Filipiak et al., 2016). Thus, it can be concluded that the content of nutritional elements in dead wood is too low to produce the biomass of a xylophage. Many wood-eating invertebrates are nevertheless able to survive and, indeed, often thrive and prosper on this low-quality food source. This can be achieved by means of advanced and expensive adaptive traits (e.g. selective feeding, overeating and selective absorption: Anderson etal., 2005; Frost etal., 2005; Hessen \& Anderson, 2008) for the

Correspondence: Michał Filipiak, Institute of Environmental Sciences, ul. Gronostajowa 7, 30-387 Krakow, Poland. Tel.: +48 12664 51 34; e-mail: michal0filipiak@gmail.com; michal.filipiak@uj.edu.pl growth and maintenance of body tissues with proper chemical composition. For dead wood, however, the mismatch appears to be too severe to be overcome by these traits alone. The C:N and $\mathrm{C}: \mathrm{P}$ ratios in dead wood may reach approximately (element: dry mass ratio/atomic ratio) N: 6500/7500 and P: 54 500/150000 (Lambert et al., 1980; Harmon et al., 1986; Weedon et al., 2009; Palviainen et al., 2010a, 2010b; Filipiak \& Weiner, 2014; Köster et al., 2015). This incompatibility must be mitigated irrespective of the digestibility of the woody high-C components of the diet: an extremely high C:other elements ratio of the food means that, to extract the required amounts of elements other than carbon, an organism must process an extraordinarily large mass of food at the same time as excreting the superfluous carbon-rich compounds, without regard to their potential digestibility. Previous studies concerning the adaptive traits required to overcome a stoichiometric mismatch do not consider such a high excess of C (Higashi etal., 1992; Darchambeau et al., 2003; Anderson et al., 2005; Frost et al., 2005; Hessen \& Anderson, 2008). The action of microbial symbionts capable of digesting cellulose may improve the digestibility of polysaccharides (Ljungdahl \& 
Eriksson, 1985; Douglas, 2009) and provide wood eaters with additional nitrogen (Roskoski, 1980), although the required net supply of nutritional elements other than $\mathrm{C}$ and $\mathrm{N}$ cannot be increased in this way. Another solution may be "nutritional supplementation' of wood by ingrowing fungi that import the matter needed to compose their tissues from the outside environment. Calculations suggest that 85 years would be required for a xylophage to accumulate the necessary amount of elements to build its body from pure dead wood, whereas this process takes only 3-4 years in nature (Filipiak \& Weiner, 2014). Accumulating the elements from dead wood infected by nutritionally rich fungal mycelia is consistent with this 3-4-year time frame (Filipiak \& Weiner, 2014) because the fungal import of non-C elements results in a fundamental rearrangement of dead wood stoichiometry during the initial phase of decay (Filipiak et al., 2016). These considerations suggest that 'dead-wood eaters' rely neither on pure dead wood as their key food source, nor on gut microbes as key nutrient deliverers. Nevertheless, to develop to adulthood, the larvae of xylophagous beetles living in an extremely nutritionally deficient environment must accumulate sufficient amounts of elements. To determine the mechanism by which nutritional balance is maintained, two common species of pine-xylem-feeding beetles are selected as model organisms: Stictoleptura rubra L. and Chalcophora mariana Dejean. These organisms occupy similar ecological niches (developing on decaying pine wood and facing stoichiometric mismatch) but belong to two different taxa (Cerambycidae and Buprestidae) and differ in body size. The beetles inhabit pine stumps in numbers that permit the collection of sufficient sample quantities for chemical analysis. The maximum development time ranges from 3 to 4 years for $S$. rubra to 6 years for $C$. mariana (Dominik \& Starzyk, 2004; Walczyńska, 2012). Over such a long period of development, the process of wood decomposition advances, and the concentration of nutrients increases. Over the time corresponding to larval development of a xylophage, the nutrient concentration may increase by 23 -fold for $\mathrm{N}$, 40-fold for $\mathrm{P}$, six-fold for $\mathrm{Cu}$, six-fold for $\mathrm{K}$ and seven-fold for $\mathrm{Fe}$ as a result of transport from the outside environment by ingrowing fungi (Filipiak \& Weiner, 2014; Filipiak et al., 2016). Thus, xylophages develop in a nutritionally dynamic environment.

The present study aims: (i) to determine the changes in body concentrations of nutritional elements $(\mathrm{C}, \mathrm{N}, \mathrm{P}, \mathrm{K}, \mathrm{Na}, \mathrm{Ca}, \mathrm{Mg}$, $\mathrm{Fe}, \mathrm{Zn}, \mathrm{Mn}$ and $\mathrm{Cu}$ ) during the ontogenesis of xylophagous beetles; (ii) to relate the ontogenetic dynamics of body composition to changes in the elemental composition of dead wood; and (iii) to identify the strategy used by xylophages to overcome the extreme nutritional poverty of dead wood.

\section{Materials and methods}

Two common species of pine xylem-feeding beetles were used: S. rubra Linnaeus (=Corymbia rubra Nakano and Obayashi, 1957 and Aredolpona rubra Viliers 1974) and C. mariana Linnaeus (=Buprestis mariana Linnaeus 1758; Coleoptera, Buprestidae). Both adult beetles and pine stumps that most likely contained beetle larvae were collected in the Niepołomice Forest (southern Poland, $50^{\circ} 05^{\prime} \mathrm{N}, 20^{\circ} 21^{\prime} \mathrm{E}$, elevation 184-212 m.a.s.l.), in the spring, summer and autumn of 2010-2012. Stumps aged 1-4 years after tree logging were hand split to collect larvae and pupae.

Raw data on the chemical composition of the wood, adult beetles and pupae were obtained from a previous investigation (Filipiak \& Weiner, 2014) (see Supporting information, Tables S1 and S2; larvae, pupae and adults were sampled at the same sites and at the same time; the larvae investigated in the present study inhabited the pine stumps described by Filipiak \& Weiner, 2014). These data were used to compare the dynamic elemental composition of growing beetles with the temporal stoichiometric changes in their potential food resulting from ongoing decay processes. The wood samples were classified by the degree of decay in accordance with Esseen et al. (1997): (i) undecayed wood - no visible changes caused by microorganisms, hard and healthy; (ii) moderately decayed wood - considerably changed by microorganisms, discolored (purple and dark brown), wet and softer than (i) but still difficult to tear apart with a knife; and (iii) highly decayed wood - many visible changes, ample layers of white or brown rotting fungi, wet, soft and easily torn apart with a knife or even by hand.

The larvae of both beetle species were divided into age classes (L1-L3 for S. rubra and L1-L4 for C. mariana) based on the maximum breadth of the head capsule. Extreme values for head capsule width were selected for the definition of classes based on discontinuities in the width distribution (for both species). A greater number of classes could not be distinguished because small individuals were pooled to reach the minimum measurable concentrations of elements in a sample. For $S$. rubra, the age classes were determined from data obtained in previous experiments (Walczyńska, 2010, 2012). The age classes used in the present study were: L1 (head capsule width $0.35-2.80 \mathrm{~mm}$ ), up to 290 days; L2 (2.89-3.66), from 290 to 620 days; and L3 (3.76-4.65), more than 620 days. There were no previous data suitable for determining an approximate age for $C$. mariana larvae. Therefore, age classes were defined arbitrarily according to the head capsule widths: L1, 0.40-2.17 mm; L2, 2.35-2.68 mm; L3, 2.90-3.36 mm; and L4 3.48-9.24 mm. These four stages cover the entire period of larval development (pupae and adults were found in the most heavily decayed stumps, although larval development may take as long as 6 years).

Insect and wood samples were freeze-dried to a constant mass. Their $\mathrm{C}$ and $\mathrm{N}$ contents were then determined using an automated analyzer (Vario EL III automatic CHNS analyzer; Elementar Analysensysteme $\mathrm{GmbH}$, Germany), whereas the contents of $\mathrm{K}, \mathrm{Ca}, \mathrm{Mg}, \mathrm{Fe}, \mathrm{Zn}, \mathrm{Mn}, \mathrm{Cu}$ and $\mathrm{Na}$ were measured via atomic absorption spectrometry (Perkin Elmer AAnalyst 200 and AAS: PerkinElmer AAnalyst 800; Perkin Elmer Inc., Waltham, Massachusetts) and the P content by colorimetry (MLE Flow injection analyzer; Medizin- und Labortechnik Engineering GmbH, Germany). Samples (one to several individuals depending on size) were mineralized by acid digestion with a solution of $4: 1.5: 1$ nitric acid $(70 \%)$, perchloric acid (65\%) and sulphuric acid $(95 \%)$ before analysis using atomic absorption spectrometry and flow injection colorimetry. Sulphanilic acid was used as a reference material for $\mathrm{C}$ and $\mathrm{N}$ analyses. Certified reference materials were used for the other nine elements (bush, NCS DC 733348; chicken, NCS ZC73016; and pork 
muscle, NCS ZC 81001, NCS Testing Technology Co., Ltd., Beijing, China).

A principal component analysis (PCA) was used to compare the multi-element stoichiometric relationships between developmental stages. The data were log transformed, centred and standardized by species but not by sample (i.e. PCA was performed on a correlation matrix; CANOCO, version 4.5; Biometrics, Plant Research International, The Netherlands). To test for significant differences between clusters in multidimensional space, which represent larvae of the same developmental stage, independent analyses of variance (ANOVA) was performed for the first and second axis scores (STATISTICA, version 10; StatSoft, Inc., Tulsa, Oklahoma). A Kruskal-Wallis test was used to test for differences $(P<0.05)$ between developmental stages in relation to the nutritional composition (STATISTICA, version 10).

\section{Trophic stoichiometric ratio (TSR)}

The degree of stoichiometric mismatch between the larvae and their food for each element, $x$, was expressed as the trophic stoichiometric ratio (TSR), a modified version of the threshold elemental ratio (TER) (Urabe \& Watanabe, 1992; Sterner \& Elser, 2002; Fagan \& Denno, 2004):

$$
T E R_{\mathrm{x}}=\left(G G E_{\mathrm{x}} / G G E_{\mathrm{c}}\right) \times(C: X)_{\mathrm{i}+1}
$$

where $G G E_{\mathrm{x}}$ is gross growth efficiency of the element $x$; $G G E_{\mathrm{C}}$ is gross growth efficiency of carbon; $i$ is trophic level; $C$ is concentration of carbon; and $X$ is concentration of element $x$. If:

$$
(C: X)_{\mathrm{i}} \geq T E R_{\mathrm{x}}
$$

then element $x$ may become a limiting factor for growth at trophic level $i+1$. The gross growth efficiencies for any given element can be experimentally measured (e.g. through feeding trials in growing animals, using foods with different contents of the studied elements). However, such data are in fact extremely scarce and are almost non-existent for elements other than $\mathrm{N}$ and $\mathrm{P}$. In practical terms, the TER index for invertebrates can only be estimated using arbitrary assumptions (Fagan \& Denno, 2004; Frost et al., 2006; Doi et al., 2010). Thus, there is a need to develop a simpler index, based on readily available data, to enable the detection of possible stoichiometric mismatches between trophic levels and comparisons between various taxa, habitats and foods. With the aim of estimating the degree of possible stoichiometric mismatch based on existing data, a simplified approach is proposed, rewriting condition (2):

$$
(C: X)_{\mathrm{i}} \geq\left(G G E_{\mathrm{x}} / G G E_{\mathrm{c}}\right) \times(C: X)_{\mathrm{i}+1}
$$

to obtain:

$$
(C: X)_{\mathrm{i}} /(C: X)_{\mathrm{i}+1} \geq G G E_{\mathrm{x}} / G G E_{\mathrm{c}}
$$

or

$$
T S R_{\mathrm{x}} \geq G G E_{\mathrm{x}} / G G E_{\mathrm{c}}
$$

Even without precise information about elemental conversion efficiencies for a given organism, it can be safely assumed that $G G E_{\mathrm{x}}>G G E_{\mathrm{c}}$ because carbon, as a metabolic energy substrate, is always partially lost as $\mathrm{CO}_{2}$. The actual values of $G G E$ for carbon and other elements depend on the growth rate, the amount of each element available in food ( $C: X$ ratio), the possible absorption efficiency, and body mass (as a result of the metabolic rate allometry). Without any information about these relationships, it may only be assumed that the gross growth efficiency for an essential nutrient may be maximized. At any rate, the larger the difference between $G G E_{\mathrm{X}}$ and $G G E_{\mathrm{c}}$, the more severe is the trophic mismatch. Based on the limited amount of published data (Fagan \& Denno, 2004), it was assumed that the minimum value of $G G E_{\mathrm{c}}$ in invertebrates would not exceed approximately 0.25 , whereas the maximum possible $G G E_{\mathrm{x}}$ may approach 1 (because it is maximized, although its actual value may be lower). Under these assumptions, the still balanced threshold ratio $\left(G G E_{\mathrm{x}} / G G E_{\mathrm{c}}\right)$ equals $1 / 0.25=4.0$. Assuming a lower $G G E_{\text {c }}$ (e.g. 0.1, with $90 \%$ of assimilated carbon excreted via respiration, which is unlikely), a threshold value of 10.0 would be obtained. With a lower actual $G G E_{\mathrm{x}}$ value (e.g. 0.5) and $G G E_{\mathrm{c}}=0.25$, the threshold may be as low as 2.0; all of these values are still within the same order of magnitude. To obtain insight into the approximate stoichiometric mismatch based on the available data, it can be arbitrarily and conservatively assumed that for $T S R_{\mathrm{x}} \geq 4.0$, element $x$ may impose a constraint on growth, with more severe mismatches indicated by even higher values. TSR is not meant to represent the actual measured TER of a given element but serves as a relative and conservative index indicating a possible stoichiometric mismatch. Various elements may be acquired, assimilated, reused and excreted differently. The TSR index assumes that noncarbon elements are assimilated from food into the body at a maximal rate $(100 \%)$. Thus, the actual mismatches in natural situations may only be greater than the values estimated as TSR.

$T S R_{x}$ was calculated as:

$$
T S R=(C: X)_{\mathrm{food}} /(C: X)_{\mathrm{consumer}}
$$

where $C$ represents the carbon concentration, and $X$ represents the concentration of element $x$. The TSR index is not dependent on the units used for the stoichiometric ratios of $C: X$ (molar or mass units).

The TSR index calculated in the present study is based on the separately estimated chemical compositions of insects and their potential food (decaying wood). The applied analytical procedures require separate sample preparation for the determination of $\mathrm{C}$ and $\mathrm{N}$ contents (dried tissue for CHNS analysis) and all other elements studied (liquid product of acid digestion of tissues for atomic absorption spectrometry and flow injection analysis). As a result of the small size of larvae and the difficulty of obtaining a perfect homogenate, the best way to obtain reliable results is to use whole specimens (or samples composed of several specimens). As a consequence, the analytical results for $\mathrm{C}$ and $\mathrm{N}$ contents were based on different specimens than the results for other elements, and comparison of TSR indices between various experimental groups was not possible based on the variance of the individual TSRs. Instead, a randomization procedure was applied and TSR values were calculated from the $C: X$ ratios of values randomly drawn from the distribution of the measured elemental contents for larval stages 
(A)
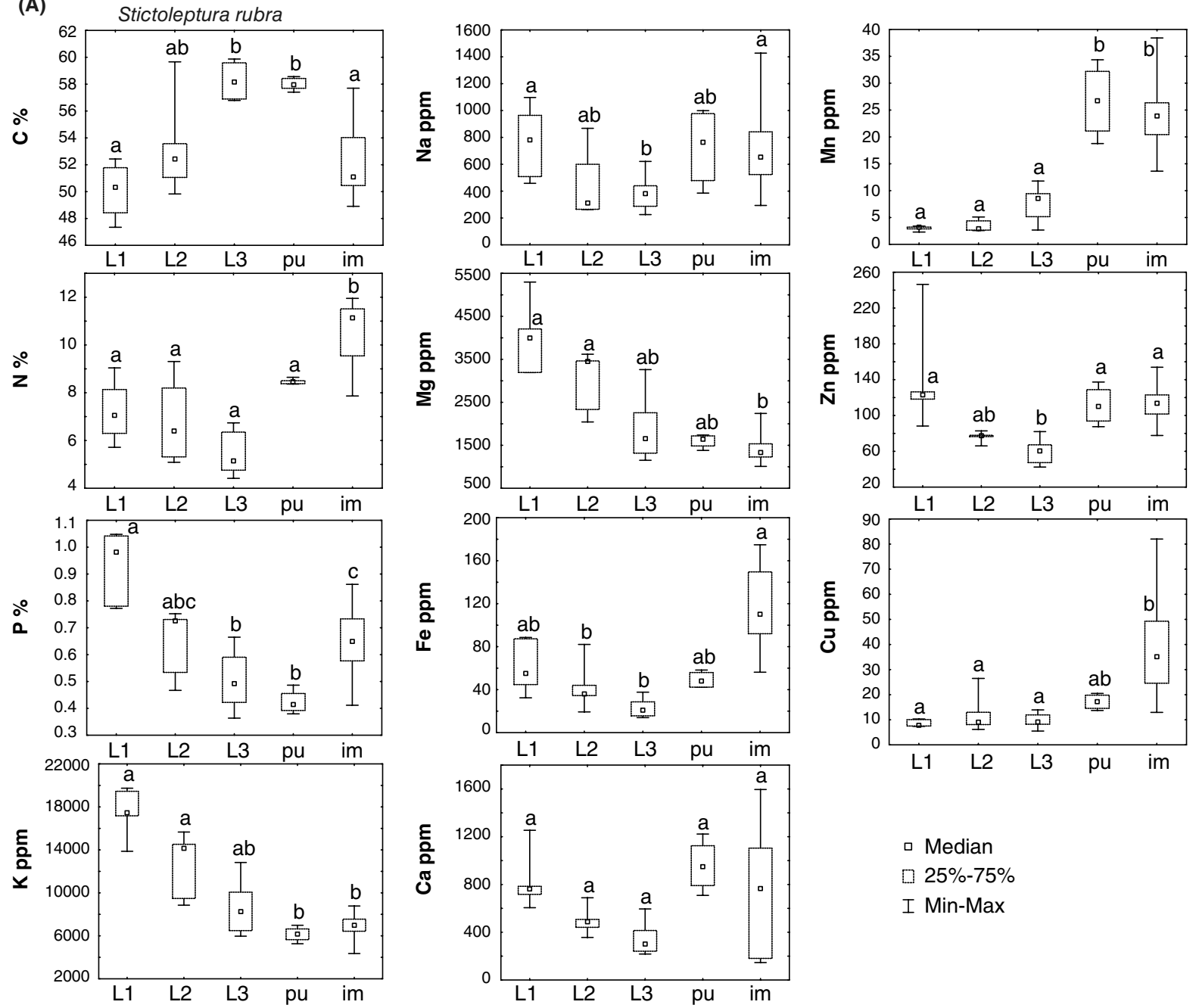

Fig. 1. Dynamics of elemental concentrations during ontogeny of two xylophagous beetle species. (A) Stictoleptura rubra. (B) Chalcophora mariana. Stages of development. L1, L2, L3 (L4): larvae of different ages (from youngest to oldest); pu, pupae; im, imagines. The letters represent significant differences in the elemental composition between developmental stages (Kruskal-Wallis test, $P<0.05)(n=3-41$, depending on stage of development and element) (see Supporting information Table S1 for details and Table S2 for absolute elemental contents). The content of C increased quickly, reached a maximum during the final larval stages or pupal stage, and decreased in imagines, whereas the concentrations of other elements decreased steadily and reached a minimum during the final larval stages, then increased again in pupae and imagines.

L1-L4 and stages 1-3 for decaying wood. The values were simply drawn from the distribution of measured elemental contents, without applying any bootstrapping technique (cf. Filipiak $\&$ Weiner, 2014). The number of possible recombined TSR values in various groups may reach approximately 1000-100 000, from which $1000 T S R$ values for each $C: X$ ratio were drawn. From these distributions, the average values and 10th and 90th percentiles were obtained.

\section{Calculation of TSRs as a measure of the current stoichiometric mismatch during larval development}

The larval body composition differs between stages as a result of the growth of new tissue (which may exhibit a different chemical composition) and simultaneous losses (egestion, moulting, and respiration). The stoichiometric balance should also involve the net change in the absolute elemental content in the increased body mass, compared with the amounts of elements ingested during the same period of time.

Thus, the increase in dry mass was first calculated between two adjacent larval stages $(\Delta m): \Delta m=m_{2}-m_{1}$, where $m_{2}$ is the mean dry mass of the older larval stage and $m_{1}$ is the mean dry mass of the younger larval stage. Then, the net increment of element $x$ during the growth phase $(\Delta x-$ absolute mass of element $x$ in $\Delta m$ ) was calculated as: $\Delta x=m_{2} \times X_{2}-m_{1} \times X_{1}$, where $X_{2}$ is the mean concentration of element $x$ in the older larval stage, and $X_{1}$ is the mean concentration of element $x$ in the younger larval stage. The ratio $X \Delta=\Delta x / \Delta m$ represents the apparent concentration of element $x$ in the mass increment. Using this ratio, 

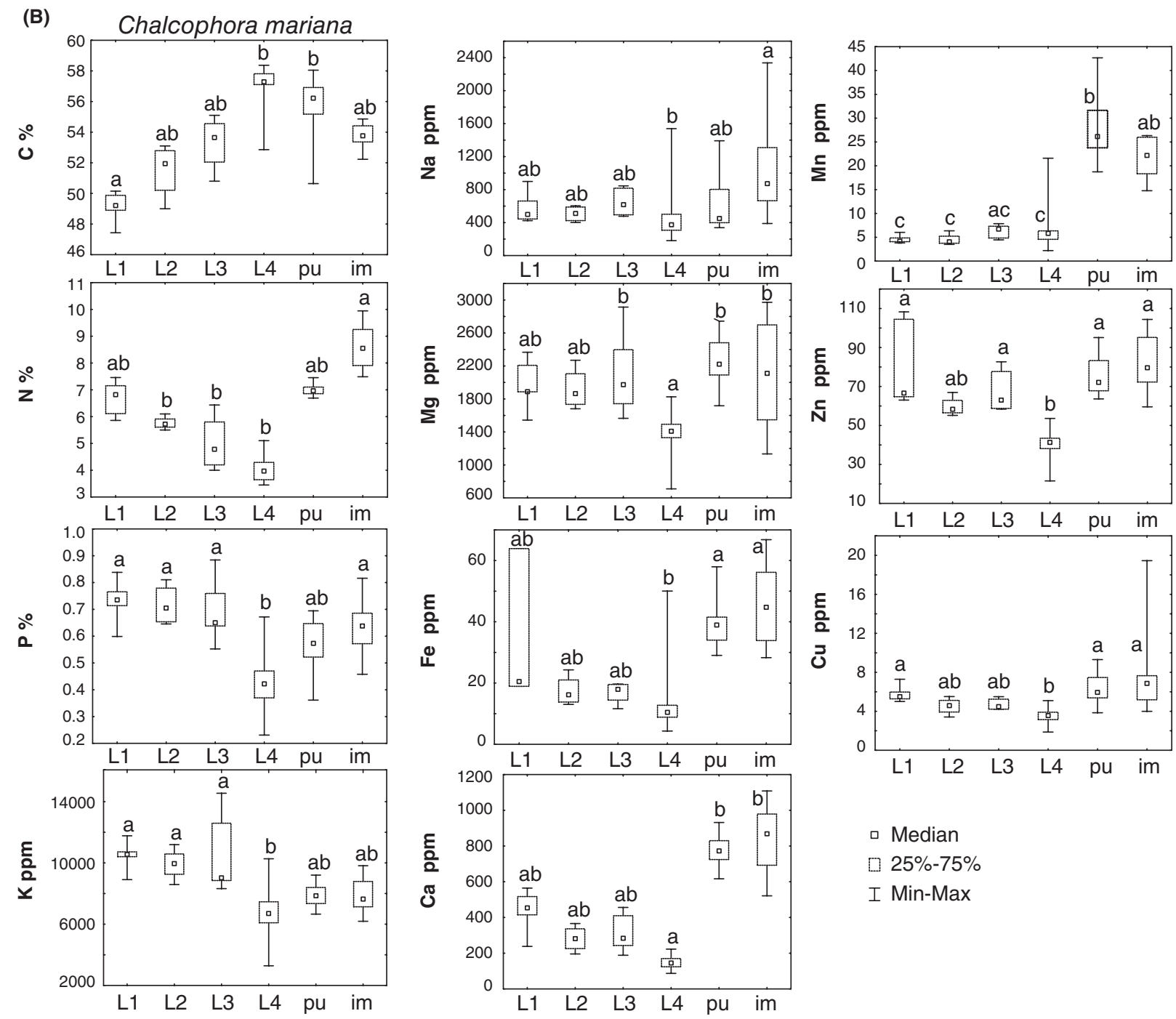

$$
\begin{aligned}
& \text { Median } \\
& 25 \%-75 \% \\
& \text { 工 Min-Max }
\end{aligned}
$$

Fig. 1. Continued.

the TSR values representing the stoichiometric balance during the mass increment were calculated by applying the procedure described earlier but using only the mean values of elemental concentrations (without randomization). The dead wood categories described earlier and the average values for the two adjacent dead wood categories (undecayed/moderately decayed and moderately decayed/highly decayed) were employed as food sources. The means were used as an approximation of the changing stoichiometry of the food during larval development.

\section{Results}

\section{Changes in the elemental composition of larvae during development}

The percentage of $\mathrm{C}$ in the bodies of both beetle species increased significantly during larval development, peaking in the oldest larvae and pupae, followed by a decrease after eclosion (Fig. 1). Other elements showed a reverse pattern (Fig. 1). Certain elements ( $\mathrm{P}$ and $\mathrm{K}$ in both species and $\mathrm{Na}$ and $\mathrm{Mg}$ in S. rubra) exhibited the highest average concentrations during the first stage of larval development, although the variations in elemental contents within each developmental stage were high, and the differences between stages were not significant in most cases (Fig. 1). The total data on relative and absolute elemental contents are presented in Supporting information, Tables S1 and S2. In both species, the patterns of changes in the concentrations of elements during development were similar.

\section{Dynamics of xylophage multi-elemental stoichiometry}

Principal component analysis of the concentrations of all studied elements in the larvae, pupae and imagines revealed similar patterns of stoichiometric changes in the body composition 
Table 1. Values of the first two principal component loadings for the principal component analysis plots in Fig. 2 for the two xylophagous species: Stictoleptura rubra and Chalcophora mariana.

\begin{tabular}{|c|c|c|c|c|c|c|c|c|c|c|c|}
\hline Axis & $\mathrm{C}$ & $\mathrm{N}$ & $\mathrm{P}$ & K & $\mathrm{Na}$ & $\mathrm{Mg}$ & $\mathrm{Fe}$ & $\mathrm{Ca}$ & Mn & $\mathrm{Zn}$ & $\mathrm{Cu}$ \\
\hline \multicolumn{12}{|c|}{ Stictoleptura rubra } \\
\hline Axis 1 & 0.64 & -0.95 & -0.31 & 0.43 & -0.66 & 0.47 & -0.93 & -0.35 & -0.78 & -0.81 & -0.82 \\
\hline Axis 2 & -0.52 & -0.01 & 0.86 & 0.87 & 0.38 & 0.82 & 0.12 & 0.29 & -0.56 & 0.40 & -0.23 \\
\hline \multicolumn{12}{|c|}{ Chalcophora mariana } \\
\hline Axis 1 & 0.58 & -0.89 & -0.80 & -0.67 & -0.68 & -0.85 & -0.90 & -0.93 & -0.69 & -0.95 & -0.88 \\
\hline Axis 2 & -0.62 & -0.21 & 0.48 & 0.61 & -0.12 & 0.06 & -0.20 & -0.25 & -0.63 & 0.04 & -0.15 \\
\hline
\end{tabular}

(A)

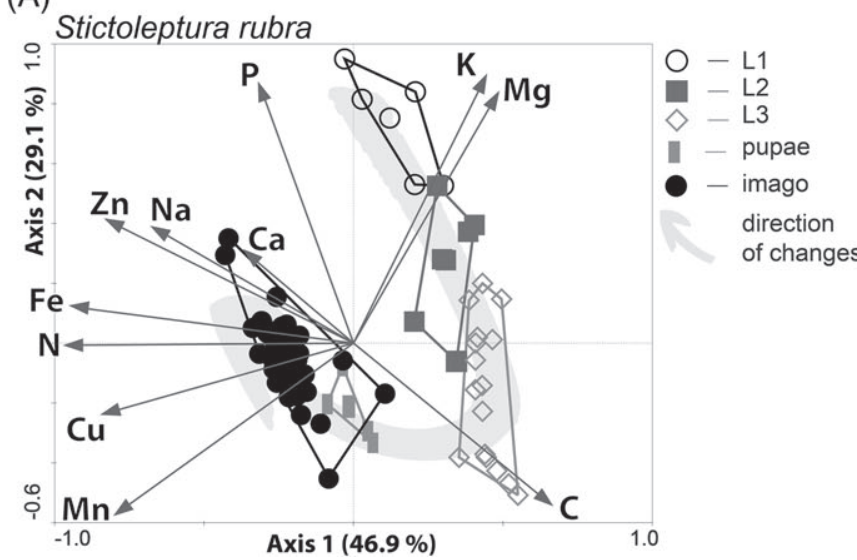

(B)

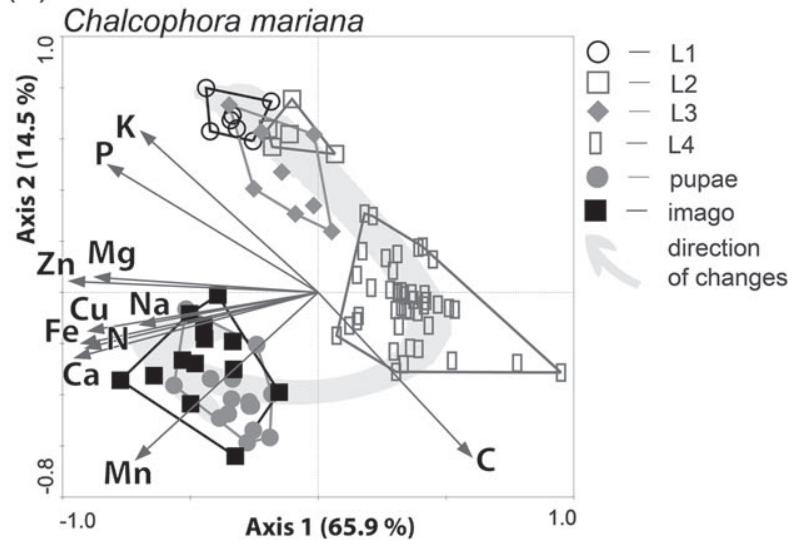

Fig. 2. Multivariate analysis of changes in body composition during ontogenesis in the two studied beetle species, Stictoleptura rubra (A) and Chalcophora mariana (B), based on 11 elements: principal component analysis (PCA) plots (first two axes). L1-L4: larval stages (L1 is the youngest, L3 or L4 is the oldest). An individual dot represents one sample, $n=71$ for $S$. rubra and 79 for $C$. mariana. Larval stages differ mainly as a result of increases in the $\mathrm{C}$ concentration and decreases in $\mathrm{P}, \mathrm{K}$ and $\mathrm{Mg}$ concentrations with age. Non-C elements are concentrated in adults (for the values of the loadings, see Table 1; for statistical analysis of score values, see Fig. 3).

during ontogenesis for the two species. The first two principal components explained $80.4 \%$ and $76.0 \%$ of the observed variance in elemental concentrations for C. mariana and S. rubra, respectively, with a prevailing contribution of the first axis, confirming a strong correlation between these variables. The first principal component primarily explained the variance in $\mathrm{N}, \mathrm{Fe}, \mathrm{Cu}$ and $\mathrm{Zn}$ contents, and the second principal component explained primarily the variance in $\mathrm{K}, \mathrm{P}$ and $\mathrm{C}$ contents, although there were differences between species, especially for $\mathrm{P}$ and $\mathrm{Mg}$ (Table 1). The PCA plots indicated that each developmental stage exhibited a specific multi-elemental stoichiometry and that, in both species, it proceeded from one stage to another along a similar trajectory in multidimensional space (Figs 2 and 3). The transition from the first to the final stage of larval development in $S$. rubra proceeded along the second axis, loaded mostly by P, K, Mg and C (Fig. 2 and Table 1), whereas, in $C$. mariana, the same trajectory ran diagonally, determined mostly by P, K and C (Fig. 2 and Table 1). The transition from the final larval stage to pupae and adults in both species proceeded along the first axis (Fig. 2), with a similar contribution of all elements (Table 1).The clusters of individuals belonging to the same larval classes differed from each other in both species, and all larval classes differed from the pupae and adults in both species, whereas the adult and pupal clusters overlapped (Fig. 2).
The ANOvas calculated for the PCA scores (Fig. 3) indicate significant stoichiometric differences between all developmental stages for $S$. rubra and between the three ( $\mathrm{a}, \mathrm{b}$ and c) stoichiometrically similar groups in $C$. mariana: (a) the first three larval stages (L1, L2, L3); (b) the oldest larval stage (L4); and (c) the pupae and imagines. In both species, the adults (after eclosion) exhibited higher concentrations of all elements except $\mathrm{C}$, although this pattern was less obvious for $\mathrm{K}$ and $\mathrm{Mg}$ in S. rubra. These nutrients appeared to be highly concentrated in the youngest larvae (L1 and L2) (Fig. 2).

\section{Changes in the elemental composition of wood during larval development}

The elemental composition of wood inhabited by larvae changed during larval development. The initial contents of elements other than $\mathrm{C}$ were low and increased considerably during the first 4 years after tree cutting (Fig. 4), a period corresponding to the developmental time of the larvae of the studied species. The relative increments of the concentrations during wood decay were highest for N (23-fold), P (14-fold), $\mathrm{Cu}$ (6.3-fold) and $\mathrm{K}$ (four-fold), as also previously shown by Filipiak \& Weiner (2014). According to the PCA results, the 
(A)

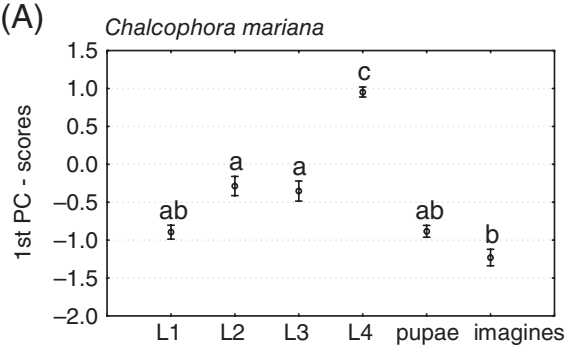

(B)

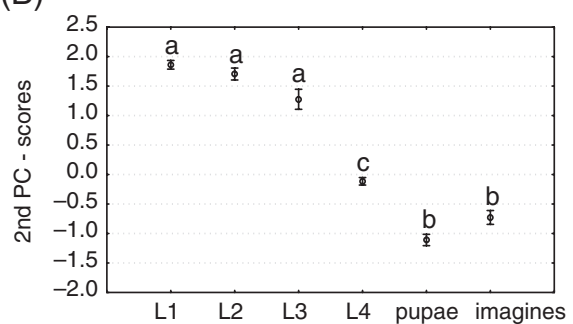

(C)

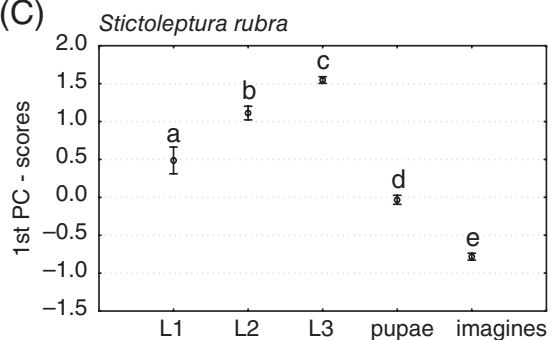

(D)

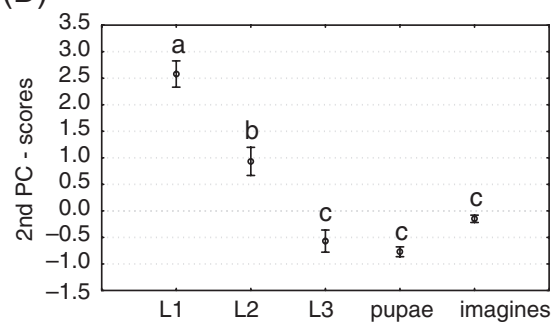

Fig. 3. The first two principal component scores for the elemental concentrations plotted for the developmental stages of Chalcophora mariana and Stictoleptura rubra. Error bars denote the SE. Values with different letters indicate significant differences in the elemental composition between larval stages, pupae and imagines [analysis of variance (ANOVA), unequal $n$, honestly significant difference test, $P<0.05$ ]. (A) Chalcophora mariana, ANOVA for the scores of the first principal component $\left(F_{6,76}=91.919, P=0.0000\right)$. (B) Chalcophora mariana, ANOva for the scores of the second principal component $\left(F_{5,86}=97.766, P=0.0000\right)$. (C) Stictoleptura rubra, ANOva for the scores of the first principal component $\left(F_{4,77}=242.25, P=0.0000\right)$. (D) Stictoleptura rubra; ANOVA for scores of the second principal component $\left(F_{4,77}=43.711, P=0.0000\right)$.

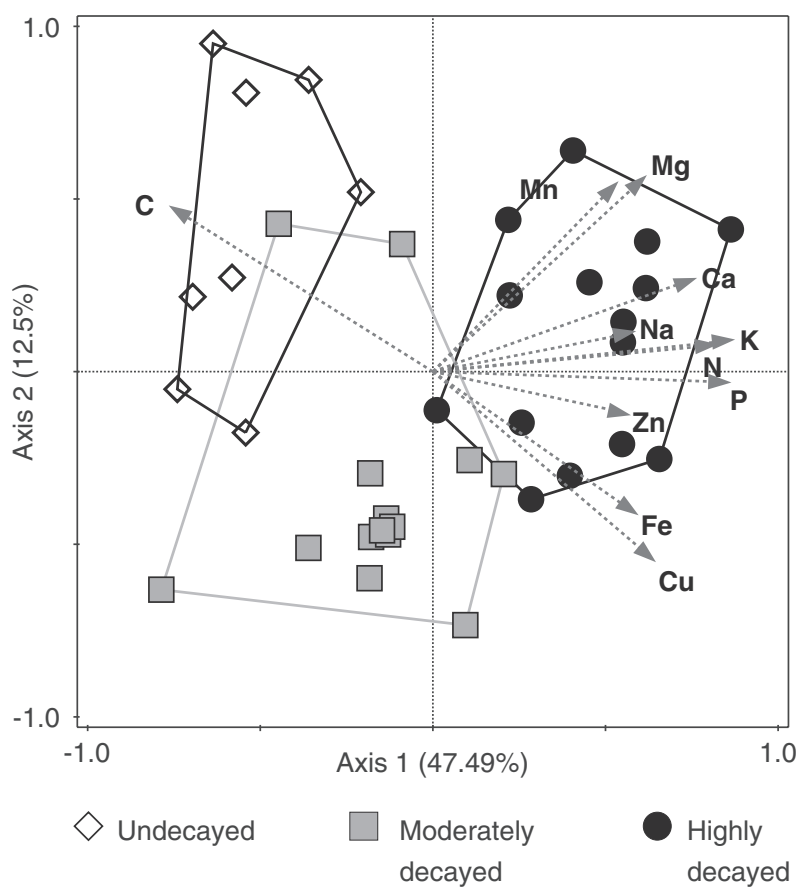

Fig. 4. Changes in the stoichiometry of dead wood inhabited by xylophagous beetles: principal component analysis (PCA) plot (first two axes). The wood samples were classified by the degree of decay. Data are from Filipiak \& Weiner (2014). An individual dot represents one sample $(n=37)$. Elements that were most limiting for xylophage development showed the greatest increase in concentrations with decay (relative to other elements; for values of loadings, see Table 2).
Table 2. Values of the first two principal component loadings for the principal component analysis plots in Fig. 4, with K, P and $\mathrm{N}$ showing the highest relative supplementation rate in decaying dead wood.

\begin{tabular}{lccccccccccc}
\hline Axis & $\mathrm{C}$ & $\mathrm{N}$ & $\mathrm{P}$ & $\mathrm{K}$ & $\mathrm{Na}$ & $\mathrm{Mg}$ & $\mathrm{Fe}$ & $\mathrm{Ca}$ & $\mathrm{Mn}$ & $\mathrm{Zn}$ & $\mathrm{Cu}$ \\
\hline Axis 1 & -0.75 & 0.81 & 0.85 & 0.86 & 0.57 & 0.60 & 0.58 & 0.74 & 0.52 & 0.56 & 0.63 \\
Axis 2 & 0.47 & 0.08 & -0.03 & 0.09 & 0.11 & 0.55 & -0.40 & 0.26 & 0.54 & -0.12 & -0.54 \\
\hline
\end{tabular}

first two axes represented $60 \%$ of the observed variation, with a prevailing contribution of the first axis (Table 2), indicating a strong correlation of all elemental contents (Fig. 4) and showing that the clusters representing samples from the final stage of wood decay were shifted from the initial stage along the first axis. The loading of the first axis was dominated by $\mathrm{K}, \mathrm{P}$, $\mathrm{N}, \mathrm{Ca}$ and $\mathrm{C}$ (loadings $>0.74$ ) (Table 2). The relatively high contribution of $\mathrm{C}, \mathrm{Mg}, \mathrm{Mn}$ and $\mathrm{Cu}$ to the loading of the second axis (Table 2) caused translocation of the cluster representing moderately decayed wood samples along the second axis (Fig. 4).

\section{Changes in nutritional mismatches during larval development}

The nutritional mismatch between the studied larvae and their food varied according to larval age and the corresponding decay stage of the dead wood (Fig. 5; for detailed data on all combinations of development and wood decay stages, see also Supporting information, Table S3). The mismatches, expressed as TSR values (Fig. 5), were more pronounced for undecayed wood and the youngest larvae and decreased with the wood 
(A)

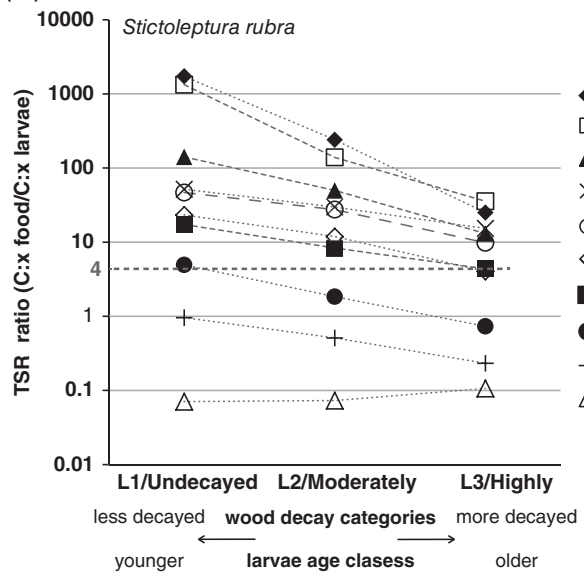

(B)

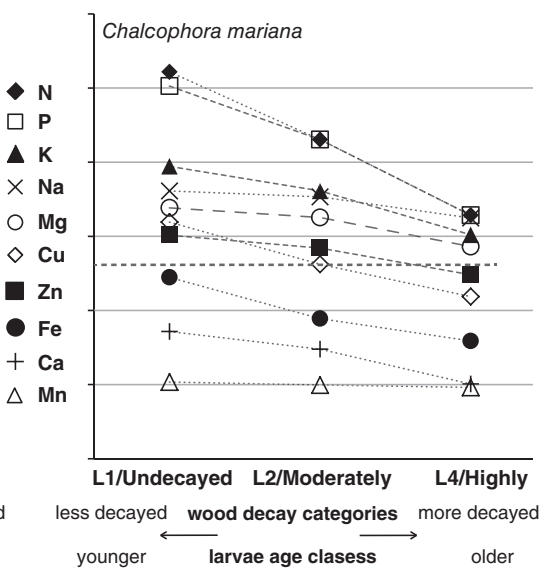

Fig. 5. Changes in trophic stoichiometric ratio (TSR) values during larval development of Stictoleptura rubra (A) and Chalcophora mariana (B) $\left(T S R_{x}=(C: X)_{\text {wood }} /(C: X)_{\text {larvae }}\right.$, where $C$ represents the content of carbon, and $X$ represents the content of element $x$ for larvae and their potential food). The TSR ratios were calculated for (i) L1 larvae and undecayed wood; (ii) L2 larvae and moderately decayed wood; and (iii) L3 (S. rubra) or L4 (C. mariana) larvae and highly decayed wood. TSR values above 4 denote limitations on development. The dotted line indicates the threshold value of $T S R=4$ (detailed results, including calculations for all of the larval stage/wood decay categories, are provided in the Supporting information, Table $\mathrm{S} 3$ ). In general, the development of xylophages is co-limited by the scarcity of $\mathrm{N}, \mathrm{P}, \mathrm{K}, \mathrm{Na}, \mathrm{Mg}, \mathrm{Cu}$ and $\mathrm{Zn}$, although the limitation decreases along the dead wood decay gradient corresponding to the larval growth of the xylophages.

Table 3. Estimated elemental composition of growing tissue during larval development of Stictoleptura rubra and Chalcophora mariana.

\begin{tabular}{|c|c|c|c|c|c|c|c|c|c|c|c|c|}
\hline & & $\mathrm{C}$ & $\mathrm{N}$ & $\mathrm{P}$ & $\mathrm{K}$ & $\mathrm{Na}$ & $\mathrm{Ca}$ & $\mathrm{Mg}$ & $\mathrm{Fe}$ & $\mathrm{Zn}$ & $\mathrm{Mn}$ & $\mathrm{Cu}$ \\
\hline & Adjacent larval stages & & $(\%)$ & & \multicolumn{8}{|c|}{ (ppm) } \\
\hline \multicolumn{13}{|c|}{ Stictoleptura rubra } \\
\hline L1 & First stage & 50.1 & 7.22 & 0.92 & 17539 & 762 & 825 & 3977 & 61.6 & 140 & 3.00 & 8.62 \\
\hline \multirow[t]{2}{*}{$x \Delta$} & $\mathrm{L} 2-\mathrm{L} 1$ & 54.0 & 6.66 & 0.56 & 11136 & 377 & 405 & 2704 & 38.0 & 58.1 & 3.67 & 13.6 \\
\hline & L3-L2 & 54.4 & 6.61 & 0.53 & 10540 & 342 & 366 & 2586 & 35.8 & 50.4 & 3.73 & 14.1 \\
\hline L3 & Last stage & 58.2 & 5.37 & 0.51 & 8640 & 382 & 339 & 1915 & 22.9 & 60.3 & 7.86 & 9.77 \\
\hline \multicolumn{13}{|c|}{ Chalcophora mariana } \\
\hline L1 & First stage & 49.1 & 6.70 & 0.73 & 10473 & 585 & 438 & 1979 & 34.5 & 81.4 & 4.60 & 5.81 \\
\hline \multirow[t]{3}{*}{$X \boldsymbol{\Delta}$} & $\mathrm{L} 2-\mathrm{L} 1$ & 52.0 & 5.55 & 0.71 & 9800 & 489 & 246 & 1907 & 13.6 & 54.8 & 4.47 & 4.23 \\
\hline & L3-L2 & 55.8 & 3.96 & 0.67 & 10970 & 834 & 350 & 2412 & 16.1 & 76.5 & 8.68 & 4.91 \\
\hline & L4-L3 & 58.2 & 3.70 & 0.32 & 5036 & 342 & 75.8 & 1082 & 9.8 & 29.7 & 6.59 & 3.05 \\
\hline L4 & Last stage & 56.7 & 4.09 & 0.44 & 6647 & 433 & 147 & 1398 & 11.9 & 40.9 & 6.49 & 3.55 \\
\hline
\end{tabular}

$X \Delta$ is the concentration of element $x$ in the body mass increment between two adjacent larval stages. Adjacent larval stages are larval age classes between which the tissue was growing (an explanation of the calculation is provided in the text); first stage is the youngest age class measured directly (L1, concentrations of elements given for the mean whole body); last stage is the oldest age class measured directly (L3 or L4, concentrations of elements referred to the mean whole-body values).

decay gradient and larval age. The TSR values indicated that the development of $S$. rubra was co-limited by the scarcity of $\mathrm{N}, \mathrm{P}, \mathrm{K}, \mathrm{Na}, \mathrm{Mg}, \mathrm{Cu}, \mathrm{Zn}$ and $\mathrm{Fe}$ and that the development of C. mariana was co-limited by the scarcity of $\mathrm{N}, \mathrm{P}, \mathrm{K}, \mathrm{Na}, \mathrm{Mg}$, $\mathrm{Cu}$ and $\mathrm{Zn}$ (Fig. 5; see also Supporting information, Table S3). The most striking mismatches (1-3 orders of magnitude) were observed for $\mathrm{N}, \mathrm{P}, \mathrm{K}, \mathrm{Na}$ and $\mathrm{Mg}$. $\mathrm{Cu}$ tended to be limiting in all larval classes of $S$. rubra and all wood categories, although only in L1 and undecayed wood in the case of $C$. mariana. $\mathrm{Zn}$ was limiting in undecayed wood and moderately decayed wood and in the L1 and L2 larvae of both species. Fe was limiting in S. rubra L1 larvae and undecayed wood. Only Ca and Mn were not limiting nutritional elements (they are available in excess in the food, Fig. 5; see also Supporting information, Table S3).
The relationship between the mismatches for $\mathrm{N}$ and $\mathrm{P}$ changed with the wood decay gradient from more severe limitation by $\mathrm{N}$ in the case of undecayed dead wood and the youngest larvae to more severe limitation by $\mathrm{P}$ or similar limitation by $\mathrm{N}$ and $\mathrm{P}$ in the case of highly decayed wood and the oldest larvae (Fig. 5; see also Supporting information, Table S3). A change in the relationship between the TSR values was also observable for $\mathrm{K}$ and $\mathrm{Na}$, as well as for $\mathrm{Zn}$ and $\mathrm{Cu}$. The value for $\mathrm{K}$ was higher than that for $\mathrm{Na}$ in undecayed wood and the youngest larvae, whereas the value for $\mathrm{K}$ was lower than that for $\mathrm{Na}$ in the oldest larvae and highly decayed wood. The value for $\mathrm{Cu}$ was higher than that for $\mathrm{Zn}$ in the youngest larvae and undecayed wood, whereas the value for $\mathrm{Cu}$ was similar to or lower than that for $\mathrm{Zn}$ in the oldest larvae and highly decayed wood (Fig. 5). 
Table 4. Trophic stoichiometric ratio (TSR) values reflecting stoichiometric mismatches experienced by xylophage larvae of Stictoleptura rubra and Chalcophora mariana during development.

\begin{tabular}{llllllllllll}
\hline $\begin{array}{l}\text { Larval } \\
\text { stage }\end{array}$ & $\begin{array}{l}\text { Wood } \\
\text { category }\end{array}$ & $\mathbf{N}$ & $\mathbf{P}$ & $\mathbf{K}$ & $\mathbf{N a}$ & $\mathbf{C a}$ & $\mathbf{M g}$ & $\mathbf{F e}$ & $\mathbf{Z n}$ & $\mathbf{M n}$ & $\mathbf{C u}$ \\
\hline $\begin{array}{l}\text { Stictoleptura rubra } \\
\text { L1 }\end{array}$ & & & & & & & & & & & \\
Lndec. & $\mathbf{9 3 5}$ & $\mathbf{1 0 0 6}$ & $\mathbf{1 3 0}$ & $\mathbf{5 1}$ & 0.92 & $\mathbf{3 7 . 5}$ & $\mathbf{4 . 9}$ & $\mathbf{1 6}$ & 0.06 & $\mathbf{2 4}$ \\
L3-L2 & Mod.-undec. & $\mathbf{2 8 7}$ & $\mathbf{1 7 2}$ & $\mathbf{5 2}$ & $\mathbf{2 3}$ & 0.39 & $\mathbf{2 2 . 2}$ & 1.7 & $\mathbf{5 . 5}$ & 0.07 & $\mathbf{7 . 9}$ \\
L3 & High.-mod. & $\mathbf{4 8}$ & $\mathbf{4 8}$ & $\mathbf{1 9}$ & $\mathbf{1 7}$ & 0.29 & $\mathbf{1 4 . 9}$ & 1.1 & $\mathbf{4 . 1}$ & 0.06 & $\mathbf{4 . 4}$ \\
Chalcophora mariana & $\mathbf{2 1}$ & $\mathbf{2 8}$ & $\mathbf{1 0}$ & $\mathbf{1 4}$ & 0.22 & $\mathbf{8 . 2}$ & 0.59 & $\mathbf{4 . 3}$ & 0.10 & 2.8 \\
L1 & Undec. & $\mathbf{8 8 5}$ & $\mathbf{8 1 0}$ & $\mathbf{7 9}$ & $\mathbf{4 0}$ & 0.50 & $\mathbf{1 9 . 0}$ & 2.8 & $\mathbf{9 . 2}$ & 0.09 & $\mathbf{1 6}$ \\
L2-L1 & Mod.-undec. & $\mathbf{2 4 8}$ & $\mathbf{2 2 6}$ & $\mathbf{4 7}$ & $\mathbf{3 1}$ & 0.25 & $\mathbf{1 6 . 3}$ & 0.64 & $\mathbf{5 . 4}$ & 0.09 & 2.5 \\
L3-L2 & Mod.-undec. & $\mathbf{1 6 5}$ & $\mathbf{1 9 7}$ & $\mathbf{4 9}$ & $\mathbf{5 0}$ & 0.33 & $\mathbf{1 9 . 2}$ & 0.71 & $\mathbf{7 . 0}$ & 0.15 & 2.7 \\
L3-L2 & High.-mod. & $\mathbf{2 8}$ & $\mathbf{5 8}$ & $\mathbf{1 9}$ & $\mathbf{3 9}$ & 0.27 & $\mathbf{1 3 . 5}$ & 0.47 & $\mathbf{6 . 0}$ & 0.13 & 1.5 \\
L4-L3 & High.-mod. & $\mathbf{2 5}$ & $\mathbf{2 7}$ & $\mathbf{8 . 5}$ & $\mathbf{1 6}$ & 0.06 & $\mathbf{5 . 8}$ & 0.27 & 2.2 & 0.10 & 0.89 \\
L4 & High. & $\mathbf{1 6}$ & $\mathbf{2 5}$ & $\mathbf{7 . 8}$ & $\mathbf{1 7}$ & 0.10 & $\mathbf{6 . 1}$ & 0.31 & 3.0 & 0.08 & 1.1 \\
\hline
\end{tabular}

Wood categories: undec., undecayed; mod., moderately decayed; high., highly decayed. For in-between categories of wood and larval stages, the mean was calculated from the two adjacent categories (for explanation, see text). Values $>4$ are shown in bold, indicating the nutritional limitation of the development of xylophages.

\section{Current stoichiometric mismatches experienced during development}

In the case of $S . r u b r a$, the stoichiometry of body mass $(\Delta m)$ that was built between two adjacent larval stages was stable throughout development and differed from the stoichiometry of the whole larvae (Table 3). In particular, the $\mathrm{Cu}$ concentration in $\Delta m$ was relatively high, whereas the $\mathrm{Zn}$ and $\mathrm{Fe}$ concentrations relatively low compared with the concentrations measured in the bodies of the youngest larvae (L1). The $\Delta m$ was also enriched in $\mathrm{C}$ (most likely because of fat deposition). In C. mariana, $\Delta m$ varied with age (Table 3 ). In this species, the $C$ content increased with increasing larval age, whereas the concentrations of other nutritional elements were lower, showing a gradient of changes from low-C, high-other elemental concentrations in L1 larvae to high-C, low-other elemental concentrations in L4 larvae. The TSRs calculated for $\Delta m$ (Table 4) showed that the current stoichiometric mismatches experienced by growing xylophages (Table 3 ) tended to be slightly less pronounced than the mismatches calculated for the whole larval bodies (Fig. 5). However, they were still extremely high and depended more on the dead wood decomposition stage than on the larval age. Thus, all of the results reported earlier based on the whole-body stoichiometry remain valid. The TSR values calculated for $X \Delta$ (concentrations of elements in the body mass built between two adjacent larval stages) indicate that the development of $S$. rubra was co-limited by the scarcity of $\mathrm{N}, \mathrm{P}, \mathrm{K}, \mathrm{Na}, \mathrm{Mg}, \mathrm{Cu}, \mathrm{Zn}$ and $\mathrm{Fe}$ and that the development of $C$. mariana was co-limited by the scarcity of $\mathrm{N}, \mathrm{P}, \mathrm{K}, \mathrm{Na}, \mathrm{Mg}, \mathrm{Cu}$ and $\mathrm{Zn}$ (Table 4).

\section{Discussion}

\section{Changes in body stoichiometry during xylophage development}

In both species, the $\mathrm{C}$ concentration increases with age and decreases after eclosion. This pattern is most likely attributable to intense fat deposition during larval growth and the subsequent exploitation of these reserves during the energetically costly morphological transformations that occur during the pupal stage. Growing tissue is also enriched in $\mathrm{Cu}$ (Table 3), particularly in $S$. rubra, which is more limited by the scarcity of this element than $C$. mariana. In both species, the concentrations of $\mathrm{K}, \mathrm{Fe}$ and $\mathrm{Zn}$ in growing tissue tend to decrease with larval age (Table 3). Almost all elements other than $\mathrm{C}$ (with the exception of $\mathrm{K}$ and $\mathrm{Mg}$ in S. rubra and $\mathrm{K}$ in C. mariana) (Figs 1 and 2) exhibit increased concentrations in adults during pupation. The contents of three elements are exceptionally high in adults: Mn in both species, $\mathrm{Cu}$ in S. rubra and $\mathrm{Ca}$ in C. mariana. A trend of higher $\mathrm{P}$ concentration in younger larvae is observed in both species (particularly in S. rubra) (Figs 1 and 2). According to the growth rate hypothesis, an increased $\mathrm{P}$ concentration is related to faster growth, and the atomic $\mathrm{N}$ : $\mathrm{P}$ ratio can be used as a measure of the P demand for growth (Elser et al., 1996, 2000 , 2003). The mean $\mathrm{N}: \mathrm{P}$ atomic ratios for all larval stages of both species initially increase in $S$. rubra $(\mathrm{L} 1 \mathrm{~N}: \mathrm{P}=6.7, \mathrm{~L} 2$ $\mathrm{N}: \mathrm{P}=9.1$, L3 $\mathrm{N}: \mathrm{P}=9: 1 ; \mathrm{L} 1=$ the youngest, $\mathrm{L} 3=$ the oldest larvae) and remain almost constant in C. mariana ( $\mathrm{L} 1 \mathrm{~N}: \mathrm{P}=7.9$, $\mathrm{L} 2 \mathrm{~N}: \mathrm{P}=6.9, \mathrm{~L} 3 \mathrm{~N}: \mathrm{P}=7.2, \mathrm{~L} 4 \mathrm{~N}: \mathrm{P}=8.0 ; \mathrm{L} 1=$ the youngest, L4 $=$ the oldest larvae). Back \& King (2013) note that the $N: P$ ratio generally increases during development in aquatic insects in association with a decreasing growth rate. The two species of xylophage that are investigated in the present study may exhibit different life histories: $S$. rubra may display rapid growth of the youngest larvae, whereas $C$. mariana may maintain a relatively constant growth rate throughout larval development.

\section{Nutritional mismatches during larval development}

During its lifetime, a xylophagous insect larva must be able to obtain all of the elements required for growth. Dead wood is extremely deficient in all of these important elements except $\mathrm{C}$; however, the wood is not nutritionally stable, and a decrease in $\mathrm{C}: \mathrm{X}$ ratios is observed during the first 4 years of decomposition (Fig. 4). This nutritional rearrangement of dead wood is a result of the development of a network of fungal connections between the soil and dead wood and the fungal ability to mobilize nutrients from the soil into stumps (Swift et al., 1979; Dighton, 2003; Filipiak \& Weiner, 2014; Filipiak et al., 2016). Fungi may connect dead wood stumps with patches of forest floor that are nutritionally rich (decomposing matter, mineral soil, bedrock rich in specific elements) and translocate nutritional elements from these patches to the stumps (Stark, 1972; Swift etal., 1979; Lodge, 1987; Boddy \& Watkinson, 1995; Dighton, 2003, 2007; Cairney, 2005; Watkinson et al., 2006; Clinton etal., 2009; Mooshammer etal., 2014; Filipiak etal., 2016). This nutritional rearrangement is the main factor responsible for the observed mitigation of stoichiometric mismatches experienced by growing larvae. The mismatches depend primarily on the stage of dead wood decay (not on the larval elemental composition; Fig. 5 and Table 4; for details, see also Supporting information, Table S3). Undecayed dead wood (least infected by fungi; Filipiak et al., 2016) presents xylophages with stoichiometric mismatches that are too high to be overcome 
(Fig. 5 and Table 4). Larval development is limited by $\mathrm{N}$ and $\mathrm{P}$ deficiencies in food, as suggested by Lemoine et al. (2014), as well as the scarcity of some minor nutrients, among which $\mathrm{K}, \mathrm{Na}, \mathrm{Mg}, \mathrm{Zn}, \mathrm{Fe}$ and $\mathrm{Cu}$ represent limiting factors (Fig. 5 and Table 3; see also Supporting information, Table S3). The limitation is mitigated during the decomposition of dead wood, although large stoichiometric mismatches remain for five elements (N, P, K, Na, Mg) (Fig. 5). These mismatches constrain larval growth, resulting in prolongation of the larval development time. The question arises: is it possible for xylophages to overcome extreme stoichiometric mismatches in any other way than relying on fungal import? Hessen \& Anderson (2008) note that an excess of $\mathrm{C}$ may be utilized to enhance fitness. They also describe mechanisms used to adjust to leftover C. However, they only consider relatively low levels of $\mathrm{C}$ excess (the highest $\mathrm{C}: \mathrm{P}$ atomic ratio noted is 600 , in contrast to the maximum value of 150000 that may occur in dead wood). The extreme mismatches observed in the present study cannot be mitigated by employing simple strategies such as releasing gaseous $\mathrm{CO}_{2}$ or increasing body temperature and metabolic rate. In the case of an extreme excesses of $\mathrm{C}$ in relation to other nutritional elements, the prevailing mass of $\mathrm{C}$ must be excreted by defecation, regardless of its potential digestibility (thus, the larvae must overfeed, which in turn may cause a decrease in nutrient absorption). Indeed, the $\mathrm{C}$ concentration in the frass of saproxylic insects is similar to that in wood (Chen \& Forschler, 2016). Digestive tract symbionts can improve the digestibility of food, supplement the diet with $\mathrm{N}$ and synthesize important organic compounds from nutrients furnished by the preliminary food or eliminate toxins (Douglas, 2009, 2011; Feldhaar, 2011; Karasov et al., 2011; Hammer \& Bowers, 2015). However, considering the law of conservation of mass, the content of any element processed by microbial symbionts cannot be changed during any chemical reaction performed by the microbes. Thus, although digestive tract symbionts can decrease $\mathrm{N}$ limitation in xylophages and do convert organic compounds, it is impossible for these symbionts to have a role in decreasing limitations resulting from the scarcity of multiple elements in food. Detritivores may overcome dietary deficiencies by feeding on microbes that cover the detritus and concentrate nutrients (Horvathova et al., 2016). Similarly, xylophages may cope with extreme stoichiometric mismatches by relying on nutritionally rich fungal tissue as a food source instead of dead wood (Filipiak \& Weiner, 2014; Filipiak et al., 2016). Thus, the strategy used by xylophages to overcome the extreme nutritional poverty of dead wood comprises (i) relying on fungal rearrangement of dead wood stoichiometry during the first years of decay, disregarding changes in the body stoichiometry of growing larvae, and (ii) prolongation of growth supported by low mortality risk (Walczyńska, 2010, 2012) and good conditions for overwintering created by dead wood (Walczyńska \& Kapusta, 2016).

\section{Roles of fungi in balancing the diet of xylophages inhabiting dead wood and in food-web dynamics}

Understanding the interactions of wood-eating beetles and fungi appears to be important for understanding the wood decomposition process and nutrient cycling in forests (Floren et al., 2015). Klironomos \& Hart (2001) describe how fungi influence food-web dynamics by supplying trees with $\mathrm{N}$ translocated from previously predated animals in exchange for the plant's carbon. Fungi redistribute $\mathrm{C}$ between trees (Klein et al., 2016). It is clear that not only $\mathrm{C}$ and $\mathrm{N}$, but also other limiting elements may be withdrawn by fungi from any source that is impossible for other organisms to reach. The life histories of xylophages are co-limited by the complex of nutritional elements required for maintaining their bodies' multi-elemental stoichiometry and for performing all physiological processes. Fungi enrich dead wood in those nutritional elements that are the most limiting for xylophage development, specifically P, N, K, $\mathrm{Cu}, \mathrm{Na}, \mathrm{Mg}, \mathrm{Zn}$ and $\mathrm{Fe}$ (Filipiak \& Weiner, 2014; Filipiak et al., 2016). The present study clarifies the dependence of xylophages on the action of fungi: xylophagous life cycles are shaped by the import of $\mathrm{N}, \mathrm{P}, \mathrm{K}, \mathrm{Na}, \mathrm{Mg}$ and $\mathrm{Cu}$ into the nutritionally extremely harsh environment of dead wood by fungi at the beginning of the decay process. As the process proceeds, dead wood becomes a more nutritionally balanced nourishment for xylophages. These changes enable xylophages to grow an adequate mass of tissue with an appropriate stoichiometry. Wood-feeding insects are ecosystem engineers that change the nutritional properties of dead wood, making the nutritive elements in dead wood available to other organisms via the insects' frass (Chen \& Forschler, 2016). Thus, fungi allow xylophages to develop, and xylophages in turn affect dead wood, contributing to wood decomposition and nutrient cycling in the forest floor.

\section{Supporting Information}

Additional Supporting Information may be found in the online version of this article under the DOI reference: DOI: $10.1111 /$ phen. 12168

Table S1. Relative elemental contents in the studied beetle larvae.

Table S2. Absolute elemental contents in the studied beetle larvae.

Table S3. Trophic stoichiometric ratios $\left(T S R_{X}=\right.$ $\left.(C: X)_{\text {wood }}(C: X)_{\text {larvae }}\right)$.

\section{Acknowledgements}

We are indebted to Ulf Bauchinger and the anonymous reviewers for their constructive critical comments. The present study was supported by the Polish Ministry of Science and Higher Education (Grant No. DS/WBiNoZ/INoŚ/DS 756) and the National Science Centre (Grant No. UMO-2011/01/B/NZ8/00103). We thank Nadleśnictwo Niepołomice (Niepołomice Forest Inspectorate) for support during the field portion of the study. We also thank Maciej Choczyński, Paweł Dudzik and Patrycja Gibas for assistance with the chemical analyses. Additionally, we thank American Journal Experts (AJE) for English-language editing of the manuscript submitted for publication. 


\section{References}

Anderson, T.R., Hessen, D.O., Elser, J.J. \& Urabe, J. (2005) Metabolic stoichiometry and the fate of excess carbon and nutrients in consumers. American Naturalist, 165, 1-15.

Back, J.A. \& King, R.S. (2013) Sex and size matter: ontogenetic patterns of nutrient content of aquatic insects. Freshwater Science, 32, 837-848.

Boddy, L. \& Watkinson, S.C. (1995) Wood decomposition, higher fungi, and their role in nutrient redistribution. Canadian Journal of Botany, 73, 1377-1383.

Cairney, J. (2005) Basidiomycete mycelia in forest soils: dimensions, dynamics and roles in nutrient distribution. Mycological Research, 109, 7-20.

Chen, Y. \& Forschler, B.T. (2016) Elemental concentrations in the frass of saproxylic insects suggest a role in micronutrient cycling. Ecosphere, 7, 1-13.

Clinton, P.W., Buchanan, P.K., Wilkie, J.P. et al. (2009) Decomposition of Nothofagus wood in vitro and nutrient mobilization by fungi. Canadian Journal of Forest Research, 39, 2193-2202.

Darchambeau, F., Faerøvig, P.J. \& Hessen, D.O. (2003) How Daphnia copes with excess carbon in its food. Oecologia, 136, 336-346.

Denno, R.F. \& Fagan, W.F. (2003) Might nitrogen limitation promote omnivory among carnivorous arthropods? Ecology, 84, 2522-2531.

Dighton, J. (2003) Fungi in Ecosystem Processes. CRC Press, New York, New York.

Dighton, J. (2007) Nutrient cycling by saprotrophic fungi in terrestrial habitats. Environmental and Microbial Relationships (ed. by C.P. Kubicek and I.S. Druzhinina), pp. 287-300. Springer Berlin, Heidelberg, Germany.

Doi, H., Cherif, M., Iwabuchi, T. et al. (2010) Integrating elements and energy through the metabolic dependencies of gross growth efficiency and the threshold elemental ratio. Oikos, 119, 752-765.

Dominik, J. \& Starzyk, J.R. (2004) Owady Uszkadzające Drewno. (Wood Damaging Insects). PWRiL, Poland.

Douglas, A.E. (2009) The microbial dimension in insect nutritional ecology. Functional Ecology, 23, 38-47.

Douglas, A.E. (2011) Lessons from studying insect symbioses. Cell Host \& Microbe, 10, 359-367.

Elser, J.J., Dobberfuhl, D.R., MacKay, N.A. \& Schampel, J.H. (1996) Organism size, life history, and N: P stoichiometry. BioScience, 46, 674-684.

Elser, J.J., Sterner, R.W., Gorokhova, E. et al. (2000) Biological stoichiometry from genes to ecosystems. Ecology Letters, 3, 540-550.

Elser, J.J., Acharya, K., Kyle, M. et al. (2003) Growth rate-stoichiometry couplings in diverse biota. Ecology Letters, 6, 936-943.

Esseen, P.-A., Ehnström, B., Ericsson, L. \& Sjöberg, K. (1997) Boreal forests. Ecological Bulletins, 46, 16-47.

Fagan, W.F. \& Denno, R.F. (2004) Stoichiometry of actual vs. potential predator-prey interactions: insights into nitrogen limitation for arthropod predators. Ecology Letters, 7, 876-883.

Feldhaar, H. (2011) Bacterial symbionts as mediators of ecologically important traits of insect hosts. Ecological Entomology, 36, 533-543.

Filipiak, M. \& Weiner, J. (2014) How to make a beetle out of wood: multi-elemental stoichiometry of wood decay, xylophagy and fungivory. PLOS ONE, 9, e115104.

Filipiak, M., Sobczyk, Ł. \& Weiner, J. (2016) Fungal transformation of tree stumps into a suitable resource for xylophagous beetles via changes in elemental ratios. Insects, 7, 13.

Floren, A., Krüger, D., Müller, T. et al. (2015) Diversity and interactions of wood-inhabiting fungi and beetles after deadwood enrichment. PLOS ONE, 10, e0143566.
Frost, P.C., Evans-White, M.A., Finkel, Z.V. et al. (2005) Are you what you eat? Physiological constraints on organismal stoichiometry in an elementally imbalanced world. Oikos, 109, 18-28.

Frost, P.C., Benstead, J.P., Cross, W.F. et al. (2006) Threshold elemental ratios of carbon and phosphorus in aquatic consumers. Ecology Letters, 9, 774-779.

Hammer, T.J. \& Bowers, M.D. (2015) Gut microbes may facilitate insect herbivory of chemically defended plants. Oecologia, 179, 1-14.

Harmon, M.E., Franklin, J.F., Swanson, F.J. et al. (1986) Ecology of coarse woody debris in temperate ecosystems. Advances in Ecological Research, 15, 133-302.

Hessen, D.O. \& Anderson, T.R. (2008) Excess carbon in aquatic organisms and ecosystems: physiological, ecological, and evolutionary implications. Limnology and Oceanography, 53, 1685-1696.

Hessen, D.O., Elser, J.J., Sterner, R.W. \& Urabe, J. (2013) Ecological stoichiometry: an elementary approach using basic principles. Limnology and Oceanography, 58, 2219-2236.

Higashi, M., Abe, T. \& Burns, T.P. (1992) Carbon-nitrogen balance and termite ecology. Proceedings of the Royal Society of London Series B, Biological Sciences, 249, 303-308.

Horvathova, T., Babik, W. \& Bauchinger, U. (2016) Biofilm feeding: microbial colonization of food promotes the growth of a detritivorous arthropod. ZooKeys, 577, 25-41.

Karasov, W.H., Martínez del Rio, C. \& Caviedes-Vidal, E. (2011) Ecological physiology of diet and digestive systems. Annual Review of Physiology, 73, 69-93.

Klein, T., Siegwolf, R.T.W. \& Korner, C. (2016) Belowground carbon trade among tall trees in a temperate forest. Science, 352, 342-344.

Klironomos, J.N. \& Hart, M.M. (2001) Food-web dynamics: animal nitrogen swap for plant carbon. Nature, 410, 651-652.

Köster, K., Metslaid, M., Engelhart, J. \& Köster, E. (2015) Dead wood basic density, and the concentration of carbon and nitrogen for main tree species in managed hemiboreal forests. Forest Ecology and Management, 354, 35-42.

Lambert, R.L., Lang, G.E. \& Reiners, W.A. (1980) Loss of mass and chemical change in decaying boles of a subalpine balsam fir forest. Ecology, 61, 1460.

Lemoine, N.P., Giery, S.T. \& Burkepile, D.E. (2014) Differing nutritional constraints of consumers across ecosystems. Oecologia, 174, $1367-1376$.

Lodge, D.J. (1987) Nutrient concentrations, percentage moisture and density of field-collected fungal mycelia. Soil Biology and Biochemistry, 19, 727-733.

Ljungdahl, L.G. \& Eriksson, K.-E. (1985) Ecology of microbial cellulose degradation. Advances in Microbial Ecology, Vol. 8 (ed. by K.C. Marshall), pp. 237-299. Springer, New York, New York.

Mooshammer, M., Wanek, W., Zechmeister-Boltenstern, S. \& Richter, A. (2014) Stoichiometric imbalances between terrestrial decomposer communities and their resources: mechanisms and implications of microbial adaptations to their resources. Frontiers in Microbiology, $5,22$.

Palviainen, M., Finér, L., Laiho, R. etal. (2010a) Phosphorus and base cation accumulation and release patterns in decomposing Scots pine, Norway spruce and silver birch stumps. Forest Ecology and Management, 260, 1478-1489.

Palviainen, M., Finér, L., Laiho, R. et al. (2010b) Carbon and nitrogen release from decomposing Scots pine, Norway spruce and silver birch stumps. Forest Ecology and Management, 259, 390-398.

Roskoski, J.P. (1980) Nitrogen fixation in hardwood forests of the northeastern United States. Plant and Soil, 54, 33-44.

Stark, N. (1972) Nutrient cycling pathways and litter fungi. BioScience, 22, 355-360.

Sterner, R.W. \& Elser, J.J. (2002) Ecological Stoichiometry. Princeton University Press, Princeton, New Jersey. 
Swift, M.J., Heal, O.W. \& Anderson, J.M. (1979) Decomposition in Terrestrial Ecosystems. University of California Press, Berkeley and Los Angeles, California.

Urabe, J. \& Watanabe, Y. (1992) Possibility of N or P limitation for planktonic cladocerans: an experimental test. Limnology and Oceanography, 37, 244-251.

Watkinson, S.C., Bebber, D., Darrah, P. et al. (2006) The role of wood decay fungi in the carbon and nitrogen dynamics of the forest floor. Fungi in Biogeochemical Cycles (ed. by G.M. Gadd), pp. 151-181. Cambridge University Press, Cambridge, U.K.

Walczyńska, A. (2010) Is wood safe for its inhabitants? Bulletin of Entomological Research, 100, 461-465.
Walczyńska, A. (2012) How does a xylem-feeder maximize its fitness? Bulletin of Entomological Research, 102, 644-650.

Walczyńska, A. \& Kapusta, P. (2016) Microclimate buffering of winter temperatures by pine stumps in a temperate forest. Climate Dynamics. DOI: 10.1007/s00382-016-3184-6.

Weedon, J.T., Cornwell, W.K., Cornelissen, J.H.C. et al. (2009) Global meta-analysis of wood decomposition rates: a role for trait variation among tree species? Ecology Letters, 12, 45-56.

Accepted 21 August 2016 